\title{
UM ESTUDO SOBRE OS PROCESSOS DE CAPACITAÇÃO DE COLABORADORES NAS INDÚSTRIAS DO SÉCULO XXI
}

\author{
A STUDY ON THE TRAINING PROCESSES OF COLLABORATORS IN THE \\ INDUSTRIES OF THE 21ST CENTURY
}

\author{
Willian di Gaetano Bassi - willian.bassi@fatec.sp.gov.br \\ Elvio Carlos da Costa - elvio.costa@fatec.sp.gov.br \\ Angelita Moutin Segoria Gasparotto - angelita.gasparotto@fatec.sp.gov.br \\ Faculdade de Tecnologia de Matão (FATEC) -SP -Brasil
}

DOI: 10.31510/infa.v16i2.640

\begin{abstract}
RESUMO
Este artigo tem por objetivo entender como os processos de capacitação dos colaboradores podem trazer benefícios e auxiliar na otimização do processo industrial, tornando suas atividades mais efetivas e seguras, potencializando assim o desenvolvimento das organizações. A metodologia utilizada abrange o levantamento bibliográfico e estudo de caso baseado em uma empresa que atua no ramo de alimentos e suplementos nutricionais localizada no interior do estado de São Paulo. Os principais resultados apontam que a criação de um programa de treinamento e desenvolvimento para os funcionários, além de suprir a necessidade de atualização constante, busca a melhoria dos processos industriais tornando-os mais eficazes. As principais conclusões são que os investimentos no processo de capacitação dos colaboradores de uma organização trarão retorno em forma de serviços, processos e operações mais planejadas, executadas e seguras bem como evitando o desperdício de insumos, matéria prima, tempo, dinheiro e garantindo desta forma a efetividade em seus processos produtivos.
\end{abstract}

Palavras-chave: Treinamento. Desenvolvimento. Qualificação Profissional. Indústrias Do Século XXI

\begin{abstract}
This article aims to understand how the processes of employees' professional qualification can bring benefits and assist in optimizing the industrial process, making their activities more effective and safer, thus enhancing the development of organizations. The methodology used covers the bibliographical research and a case study based on a company that operates in the food and nutritional supplements sector located in the state of São Paulo. The main results indicate that the creation of a training and development program for employees, besides meeting the need for constant updating, seeks the improvement of industrial processes making them more effective. The main conclusions are that investments in the qualification process of employees will bring return in the form of more planned and safe services, processes and operations, as well as avoiding the waste of inputs, raw material, time and money, thus guaranteeing the effectiveness of its production processes.
\end{abstract}

Keywords: Training. Development. Professional Qualification. 21ST century industry 


\section{INTRODUÇÃO}

Atualmente a sociedade vive a Era do Conhecimento, isto posto é inegável que aqueles que possuem conhecimento têm maior destaque. Neste contexto o capital intelectual tem se tornado um importante recurso para as organizações tornando-o um recurso intangível e difícil de ser mensurado. Em suas pesquisas (VARGAS et al., 2008, p. 1) descrevem que "As mudanças econômicas das últimas décadas têm gerado uma sociedade na qual o principal recurso é o conhecimento. A expressão capital intelectual (CI) tem sido usada na literatura para se referir aos intangíveis".

As empresas por si só não conseguem gerar conhecimentos sem seu capital humano, esta é uma atividade inerente aos profissionais que atuam na organização, para Edvinsson e Malone (1998, p. 31), "toda capacidade, conhecimento, habilidade e experiência individual dos empregados e gerentes estão incluídos no termo capital humano". Assim sendo a empresa necessita deste capital pois ideias, estratégias e projetos inovadores advém da criatividade e conhecimento e estas são competências do capital humano.

Outro fator que se deve levar em consideração ao investir no Treinamento e Desenvolvimento dos colaboradores é a constante evolução tecnológica, haja visto que cada vez mais há a procura por produtos personalizados com maior qualidade e menores custos devido a isto está surgindo um novo conceito de indústria, a Industria. 4.0.

Santos at al. (2018) em sua pesquisa definem a indústria 4.0 da seguinte forma:

Considerada por alguns académicos e empresários como a $4^{\mathrm{a}}$ revolução industrial (BITKOM et al., 2016) a Indústria 4.0 é um dos termos utilizados para descrever a estratégia de alta tecnologia promovida pelo governo alemão que está sendo implementada pela indústria. Abrange um conjunto de tecnologias de ponta ligadas à internet com objetivo de tornar os sistemas de produção mais flexíveis e colaborativos. Nessa abordagem, as máquinas usam auto-otimização, auto-configuração e até mesmo inteligência artificial para completar tarefas complexas, a fim de proporcionar eficiências de custo muito superiores e bens ou serviços de melhor qualidade (BAHRIN et al., 2016). Através da implementação generalizada de sensores no ambiente de produção, os mundos físico e virtual fundem-se, dando origem aos Cyber Physical Systems (CPS). Esses sistemas conectados através da Internet of Things (IoT) interagem uns com os outros, usando protocolos padrão baseados na internet, e analisam dados para prever falhas e adaptar-se às mudanças (THE BOSTON CONSULTING GROUP, 2015).

Este artigo foi desenvolvido bom base na literatura disponível e no estudo de caso de uma empresa que atua no ramo de alimentos e suplementos nutricionais localizada no interior do estado de São Paulo e tem por objetivo, colaborar para a compreensão dos benefícios de utilizar tecnologias e métodos de gestão para a potencializar o desenvolvimento das 
organizações e seus colaboradores, bem como contribuir com a literatura nesta área de conhecimento.

\section{FUNDAMENTAÇÃO TEÓRICA}

\subsection{Capacitação de Colaboradores}

Chiavenato (1996), define que as empresas são principalmente constituídas de inteligência, e isto apenas as pessoas possuem, o capital humano somente será bem utilizado quando for corretamente empregado e administrado. Neste sentido, a administração de recursos humanos torna-se prioritária em relação a qualquer outro recurso, como máquinas, equipamentos, instalações. As organizações que possuem essa visão certamente serão bemsucedidas, pois entenderam que os seus funcionários são os elementos impulsionadores do resultado, bem como o investimento feito nestas pessoas se realizado de maneira correta, trará retorno à empresa.

O capital humano agrega valor devido a "contribuição efetiva ao patrimônio de conhecimentos que permite à organização manter suas vantagens competitivas no tempo" (DUTRA, 2002, p. 126) e por isto não deve ser desprezado pelas organizações.

Com o desenvolvimento das relações humanas, além da necessidade técnica de treinar o profissional, não é mais possível conceituar o colaborador como uma pessoa que apenas que busca o seu salário e nada mais, há várias outras necessidades que o ser humano possui e busca satisfazê-las. Este é um dos motivos que se torna necessário além da capacitação técnica ter como objeto as relações interpessoais e a integração do indivíduo com a organização.

Fazendo uso dos treinamentos, a organização pode manter seus colaboradores sempre atualizados no que se refere a novas técnicas, conceitos de trabalho e tecnologias.

Podemos conceituar treinamento da seguinte forma, dentre as várias que ele possui:

Treinamento é o processo de desenvolver qualidades nos recursos humanos para habilitá-los a serem mais produtivos e contribuir melhor para o alcance dos objetivos organizacionais. O propósito do treinamento é aumentar a produtividade dos indivíduos em seus cargos, influenciando seus comportamentos. (CHIAVENATO, 1999, p.295)

Para que a organização possa aprimorar seus processos e alcançar seus propósitos, há a necessidade de desenvolver seus colaboradores através da capacitação (treinamento e desenvolvimento), incrementando assim suas habilidades técnicas ou comportamentais.

Treinamento é o processo educacional de curto prazo aplicado de maneira sistemática e organizada, através do qual as pessoas aprendem conhecimentos, atitudes e habilidades em função de objetivos definidos. (CHIAVENATO, 199, p.295)

De acordo com Milkovich (2000), o treinamento deve ser executado levando em 
consideração qual o tipo desejado:

- Integração: possui o objetivo de adaptar as pessoas à empresa;

- Técnico-Operacional: possui o objetivo de capacitar o colaborador para desenvolver funções específicas;

- Gerencial: possui o objetivo de fomentar e desenvolver competências técnicas, administrativas e comportamentais;

- Comportamental: possui o objetivo de solucionar problemas das interrelações no contexto do trabalho.

As pesquisas realizadas pelo autor destacam que há diferenças entre treinamento e desenvolvimento de pessoas. Mesmo que os métodos possam ser similares, suas concepções são diferentes. O treinamento tem seu enfoque (objetivo) na função que o profissional desenvolve ou começará a desenvolver ou seja o cargo atual, fazendo com que suas habilidades para esta função sejam melhoradas (metodologia de trabalho, boas práticas de produção, segurança do trabalho, uso de novos equipamentos e tecnologias são exemplos para a aplicação do treinamento). Já o desenvolvimento busca melhorar ou desenvolver habilidades visando novas funções, cargos e desafios, neste caso o profissional procura mais conhecimentos novas formações. As empresas podem adotar programas de incentivo para que seus funcionários busquem o desenvolvimento de suas habilidades, tornando desta forma este profissional apto a assumir funções de gerência e tomada de decisões na organização, este modelo leva mais tempo e recursos, podendo utilizar como exemplo as faculdades corporativas ou parcerias com centros universitários.

Uma análise crítica que pode ser feita até o momento é que desenvolvimento de colaboradores que já atuam na organização pode ser muito útil para a continuidade do bom funcionamento da empresa, pois com o passar dos anos e com a saída de profissionais (aposentadoria ou migração para outras empresas), estas lacunas serão preenchidas mais facilmente por profissionais bem capacitados. É necessário pontuar que há a possibilidade de que o colaborador uma vez graduado e com novos conhecimentos possa sair da organização para prestar atuar em outra, por isto é necessário criar mecanismos para compensação, como por exemplo tempo mínimo de trabalho para recuperação do que foi investido ou a devolução do montante caso o profissional deseje sair imediatamente da empresa.

Neste Sentido, Marras (2002, p. 153) elucida:

[...] treinamento deve ser necessariamente um programa de investimento e não de despesa. A diferença deve estar representada pelo retorno do capital investido, recebido dos resultados do trabalho póstreinamento, quando comparado àquele recebido pré-treinamento. Assim, o levantamento de necessidade de treinamento e, por via de consequência o próprio treinamento quando bem gerenciado não custo, mas sim um investimento, pois dará certamente o retorno desejado pela organização. 
É importante destacar que não se pode deixar de considerar que a falta de treinamento do colaborador pode gerar consequências como acidentes, perda de qualidade, desperdício de recursos (financeiros, tecnológicos, materiais e pessoal).

[...] torna-se moroso na execução de seu trabalho, perde-se facilmente, erra a todo o momento, inutiliza material, perde tempo, perde qualidade. Isto irrita o gerente, o cliente, o colega e o próprio funcionário" (CHIAVENATO, 2000, p.48).

Diante disso é possível contextualizar a importância da implantação de programa de treinamento e desenvolvimento. Todavia para que ele seja eficaz é preciso realizar previamente o levantamento de necessidade de treinamento (LNT) é importante estar bem definido, como define Marras (2002, p 150), “o que deve ser treinado e o que deve ser aprendido?”.

O levantamento deve detectar as carências em dois cenários diferentes, o primeiro é quando os problemas já estão instalados e causando danos e o segundo é quando procura prevenir que problemas aconteça, antecipando a mudanças.

O Levantamento de Necessidade de Treinamento (LNT) faz uso de vários instrumentos para pesquisa e coleta de informações dentre eles os mais comuns são: questionários, entrevistas, aplicação de testes e exames, observação do trabalho desenvolvido, folha de avaliação de desempenho entre outros.

Finalizado o levantamento, a próxima etapa é o planejamento do programa de treinamento nela são desenvolvidas as análises e coordenação das ações consideradas prioritárias e necessárias para serem implementadas nos módulos de aprendizagem. Deve-se considerar que esta etapa é o elo entre as políticas, diretrizes e ações formais e informais que regem as relações organizacionais. É no planejamento que se estabelece a prioridade entre o que é necessário e o que é possível executar, considerando os recursos disponíveis e as necessidades gerais.

[...] determinada a natureza das habilidades, conhecimentos ou comportamentos terminais desejados como resultado de treinamento, o próximo passo é a escolha das técnicas a serem utilizadas no programa de treinamento no sentido de otimizar a aprendizagem, ou seja, alcançar o maior volume de aprendizagem, com o menor dispêndio de esforço, tempo e dinheiro. (CHIAVENATO, 1993, p428).

Finalizado o levantamento de necessidade de treinamento e o planejamento a próxima etapa do processo para implantar o programa de treinamento e desenvolvimento é a execução, ou seja, a aplicação prática daquilo que foi programado para atender a necessidade da organização.

Dessa forma, Chiavenato (1993, p. 435) salienta que a:

Execução do treinamento pressupõe sempre o binômio: instrutor $\mathrm{X}$ aprendiz (...) o treinamento pressupõe uma relação de instrução $X$ aprendizagem", diferenciando que a instrução é "o ensino organizado de certa tarefa ou atividade. Aprendizagem é a incorporação daquilo 
que foi instruído ao comportamento do indivíduo. Portanto aprender é modificar o comportamento em direção àquilo que foi instruído.

A última etapa é a avaliação que na perspectiva de Marras (2003, p. 159) ela objetiva: "aferir os resultados conseguidos comparativamente àquilo que foi planejado e esperado pela organização" considerando que para isso, "todo módulo deve ter sido previamente planejado e programado para que ao seu término, haja a possibilidade de mensurar os resultados conseguidos".

Para garantir que os investimentos, planejamento e esforços para organizar e colocar em prática o programa de Treinamento e Desenvolvimento estão sendo bem aplicados e gerando as melhorias esperadas na eficiência, eficácia e efetividade dos processos bem como qual seu impacto para a organização. Para a correta avaliação do projeto a empresa deve estabelecer objetivos, metas e indicadores para desta forma saber se obteve sucesso ou não, sem esta avaliação fica impossível controlar o projeto.

Chiavenato (1993, p.436) sugere uma forma de avaliar o treinamento através de uma abordagem em três níveis:

1. Avaliação ao nível organizacional. O treinamento é um dos meios para aumentar a eficiência e deve proporcionar resultados, como:

- Aumento da eficácia organizacional;

- Melhoria da imagem da empresa;

- Melhoria do clima organizacional;

- Melhores relacionamentos empresa X empregados;

- Facilidade nas mudanças e na inovação;

- Aumento da eficiência.

2.Avaliação ao nível dos recursos humanos, deve proporcionar resultados, como:

- Redução da rotação de pessoal;

- Redução do absenteísmo;

- Aumento da eficiência individual dos empregados;

- Aumento das habilidades das pessoas;

- Elevação do conhecimento das pessoas;

- Mudanças de atitudes e de comportamentos das pessoas.

3.Avaliação ao nível das tarefas e operações pode proporcionar resultados como: 
- Aumento da produtividade;

- Melhoria da qualidade dos produtos e serviços;

- Redução no tempo de treinamento;

- Redução do índice de acidentes;

- Redução do índice de manutenção de máquinas e equipamentos.

De maneira geral, ao avaliar os investimentos (recursos) e os fatores indicativos do treinamento permite que a organização mensure a relação custo-benefício com o aprendizado obtido pelo colaborador entendendo que "o treinamento não é despesa mais investimento preciso cujo retorno é altamente compensador para a organização" (CHIAVENATO, 1993, p. 415).

Para atingir a efetividade desejada há a necessidade de um programa contínuo de treinamento e para que a empresa alcance níveis mais altos, também é necessário o fomento do desenvolvimento a médio prazo dos funcionários através do incentivo para que estes ingressem em cursos técnicos ou superiores.

Há formas com custos mais baixos para a realização dos treinamentos, para isso, a alternativa está no uso da tecnologia, que vai além dos dispositivos móveis e das salas de videoconferência. A realidade virtual e a realidade aumentada também podem e devem ser amplamente utilizadas. Este recurso nada mais é do que projetar para o espaço físico elementos virtuais interativos.

A realidade virtual possibilita a redução de custos. Existem óculos 3D de baixo valor disponíveis no mercado, que podem ser utilizados para realizar treinamentos em ambientes artificiais. Pode-se usar como exemplo o Google Cardboard ${ }^{l}$ com ele é possível montar ou adquirir um visor para realidade virtual e inclusive criar aplicações em realidade virtual esta opção requer baixo investimento financeiro, porém necessita de um profissional de tecnologia para a criação das aplicações, que podem ser personalizadas para a necessidade da organização, esta é uma das opções que o gestor pode encontrar no mercado caso opte por realizar o programa de Treinamento \& Desenvolvimento (T\&D) fazendo uso de tecnologias virtuais. Uma companhia aérea, por exemplo, pode simular um voo para capacitar os pilotos ao invés de utilizar um avião, outro exemplo é na área de engenharia. Os profissionais podem acompanhar o andamento de obras, observando os detalhes das estruturas com este recurso.

Vale ressaltar que a realidade aumentada amplia as formas de aprendizagem, transformando-a em algo mais marcante e facilitando a assimilação do conteúdo. Ao tornar a situação algo real, possibilitando a imersão e a capacidade de interagir, o colaborador retém melhor a informação e passa a ter um entendimento mais amplo da empresa. A criação destes tipos de ambientes facilita a rápida absorção do conhecimento, pois a simulação é idêntica à

\footnotetext{
${ }^{1}$ Cardboard é o aplicativo oficial de realidade virtual do Google. Ele foi feito para os usuários usarem com o visualizador do Google Cardboard, que nada mais é do que os óculos de realidade virtual da empresa.
} 
realidade.

De acordo com análises do Conferência Gartner Data \& Analytics (GARTNER, 2015), o interesse de empresas em usar a realidade aumentada para formar funcionários, aumentar a efetividade da produção e aumentar a segurança dos processos têm crescido muito nos últimos 18 meses. Os investimentos em aplicações dessa tecnologia estão em crescimento e deverá ultrapassar US \$ 2,5 bilhões em 2018.

Outra ferramenta que pode ser explorada para o programa de treinamento, somandose ao treinamento virtual, por exemplo são a criação manuais de boas práticas, processos produtivos e segurança, fazendo uso da tecnologia de realidade aumentada para que desta forma fique mais simples a compressão do conteúdo que o manual aborda. Desta forma o colaborador pode fazendo o uso de tablets, celulares ou outro dispositivo ter acesso a várias e importantes informações sobre o tema a qual desse-se aprender mais ou possui dúvidas quanto a metodologia de trabalho ou questões técnicas como manutenção de um equipamento.

\section{PROCEDIMENTOS METODOLÓGICOS}

A metodologia de pesquisa deste artigo abrange o levantamento bibliográfico, estudo de caso e entrevista com aplicação de questionário aos responsáveis pelo gerenciamento industrial da unidade visitada.

O conceito de metodologia é assim definido por Freitas e Prodanov (2013, p. 14) "a metodologia é a aplicação de procedimentos e técnicas que devem ser observados para construção do conhecimento, com o propósito de comprovar sua validade e utilidade nos diversos âmbitos da sociedade".

A pesquisa bibliográfica, que é assim definida por Rampazzo (2005, p. 53) "procura um problema a partir de referências teóricas publicadas (em livros, revistas etc.). Pode ser realizada independentemente, ou como parte de outros tipos de pesquisa". Segundo Yin (2010, p. 39), "o estudo de caso é uma investigação empírica que investiga um fenômeno contemporâneo em profundidade e em seu contexto de vida real, especialmente quando os limites entre o fenômeno e o contexto não são claramente evidentes".

Para a realização do estudo de caso o pesquisador analisou a empresa e durante visitação a planta industrial notou que grande parte dos funcionários era jovem, no decorrer da entrevista o responsável pela empresa informou que o perfil dos colaboradores é em sua maioria jovens, sendo que para vários destes funcionários este é seu primeiro emprego, e ao ser contratado o profissional passa apenas por um processo de integração no período da manhã, à tarde já assume sua função na fabricação dos produtos, por um período curto de tempo outro colaborador com mais experiência o auxilia em seus afazeres até que este esteja apto para trabalhar sozinho. Deve-se registrar que a empresa possui eficiência em sua produção e certificação sobre a qualidade dos seus métodos e produtos, o intuito desta pesquisa é mostrar quão benéfico é a inclusão do programa de Treinamento \& Desenvolvimento (T\&D) para otimizar e melhorar os processos bem como aumentar o conhecimento do principal recurso de uma organização o capital humano. 


\section{RESULTADOS E DISCUSSÕES}

Durante o estudo de caso o pesquisador pode observar que a empresa conduz seus trabalhos de forma eficiente e que com a implantação de um programa de Treinamento \& Desenvolvimento (T\&D) nesta ou em qualquer empresa irá contribuir muito para o desenvolvimento da organização e dos colaboradores, otimizando e garantindo a segurança e qualidade de seus processos.

A criação de um programa de treinamento e desenvolvimento para os funcionários, além de suprir a necessidade de atualização constante, busca a melhoria dos processos industriais tornando-os mais eficazes, pois um treinamento realizado de forma adequada e bem direcionada a necessidade da empresa, auxilia nos trabalhos melhorando a qualidade e a eficiência da produção. Outro benefício do programa é o de preparar os colaboradores para futuros cargos de gestão na organização. As empresas poderão contar com novas tecnologias para ampliar suas opções de treinamento de seus funcionários, fazendo uso da realidade aumentada e realidade virtual pois estas tecnologias estão em crescimento constante e com grande aporte financeiro. Esta tecnologia pode ser utilizada por exemplo para facilitar a manutenção de máquinas e equipamentos, a realidade aumentada poderá facilitar a solução de problemas e diminuir o tempo de parada pois com ela o funcionário poderá com maior agilidade para encontrar o defeito e saber como deverá repará-lo ou mesmo criar situações hipotéticas para treinamento.

Pode ser observado neste trabalho que investir em treinamento e desenvolvimento dos colaboradores geram retornos positivos e altamente compensadores para a empresa.

\section{CONSIDERAÇÕES FINAIS}

Atualmente, as rápidas transformações dos modelos socioeconômicos, revolução digital, redes sociais como forma de comunicação de massa o grande volume e a facilidade de acesso a dados bem como o advento da quarta revolução industrial (indústria 4.0), exigem que os profissionais sejam melhores preparados e que busquem constantemente desenvolver suas habilidades técnicas e conceituais.

Com o mercado globalizado e competitividade alta, a inovação passou a ser fator vital na continuidade das organizações em suas atividades. Ideias, estratégias e projetos inovadores advém da criatividade e conhecimento, sendo todas estas competências do capital humano.

A tendência das grandes corporações é o desenvolvimento profissional de seus colaboradores, fazendo com que o treinamento e desenvolvimento seja visto como estratégia corporativa. A busca por conhecimento agrega muito ao profissional, desta forma ele torna-se mais eficiente e garante o retorno deste investimento através dos ganhos proporcionados para a empresa.

No que tange a empresa estudada, conclui-se que apesar da eficiência em seus processos, com a implantação do programa de T\&D ela conseguirá atingir patamares mais elevados, tanto em qualidade quanto em melhorias em sua produção, haja visto que em seu ramo de atuação os consumidores são muito exigentes com a qualidade dos produtos e quanto maior o nível técnico de seus colaboradores suas operações serão melhores e mais efetivas. 
Também haverá ganho em segurança no trabalho de seus colaboradores evitando acidentes e paradas não programadas, garantindo assim que ela continue a se desenvolver e crescer de maneira planejada e bem estruturada.

Com o treinamento e desenvolvimento dos funcionários a empresa qualificará sua mão de obra, aumentando o nível técnico de seus colaboradores e podendo desta forma melhorar sua produtividade. Há também a possibilidade de trabalhar com as habilidades comportamentais da sua equipe fazendo com que a todos se desenvolvam.

Pode-se dizer por meio do trabalho empreendido que as organizações empresariais podem ter ganhos significativos ao implementar projetos que visem o treinamento e desenvolvimento de seus colaboradores, haja visto que este investimento retornará em forma de serviços, processos e operações mais planejadas e executadas devido o profissional que as executa ter maior conhecimento técnico para desenvolve-las com efetividade e segurança bem como evitando o desperdício de insumos, matéria prima, tempo dinheiro também evitando indisposição com os clientes. Além disto, o incentivo ao desenvolvimento do colaborador, garante a empresa mão de obra especializada para funções vitais objetivando o bom funcionamento das suas operações no futuro, pois os gestores (tomadores de decisão) tendem a com o tempo sair das empresas e neste momento deve-se ter profissionais a altura e bem preparados para assumir tais posições. O setor de recursos humanos deverá coordenar o levantamento da necessidade de treinamento e desenvolvimento, planejar juntamente com os gestores da empresa, executar e fazer a avaliação, desta forma garantirá a eficiência do programa.

\section{REFERÊNCIAS}

CASTANHA, L. A. Como a realidade aumentada pode ajudar nos treinamentos das empresas. Disponível: <https://canaltech.com.br/negocios/como-a-realidade-aumentadapode-ajudar-nos-treinamentos-as-empresas-45359/> Acesso: 26 agosto 2019, 22:05h.

CHIAVENATO, I. Como transformar o RH (de um centro de despesa) em um centro de lucro. São Paulo: Makron Book, 1996. 210 p.

Gestão de Pessoas: o novo Papel dos Recursos Humanos nas organizações. Rio de Janeiro: Campus, 1999. 491 p.

Recursos Humanos. São Paulo: Atlas, 1993. 515 p.

Treinamento e Desenvolvimento de Recursos Humanos: como incrementar talentos na empresa. São Paulo: Atlas, 1999. 224 p.

DUTRA, J. S. Gestão de pessoas: modelo, processos, tendências e perspectivas. São Paulo: Atlas, 2002.

EDVINSSON, L.; MALONE, M. S. Capital Intelectual: descobrindo o valor real de sua empresa pela identificação de seus valores internos. São Paulo: Makron Books, 1998. 
FREITAS; P. Metodologia do Trabalho Científico: métodos e técnicas da pesquisa e do trabalho acadêmico. 2. ed. Novo Hamburgo: Universidade Feevale, 2013.

MARRAS, J. P. Administração de Recursos Humanos: do operacional ao estratégico. São Paulo: Futura, 2002. 352 p.

MILKOVICH, G. T. Administração de Recursos Humanos: treinamento. São Paulo, Editora Atlas, 2000. $536 \mathrm{p}$.

RAMPAZZO, L. Metodologia Científica: para alunos dos cursos de graduação e pósgraduação. 3. ed. São Paulo: Edições Loyola, 2002.

SANTOS, B. P., ALBERTO, A., LIMA, T. D. F. M., \& Charrua-Santos, F. M. B. (2018). Industry 4.0: Challenges And Opportunities. Revista Produção E Desenvolvimento, 4(1), 111-124. https://doi.org/10.32358/rpd.2018.v4.316

VARGAS, Vera do Carmo Comparsi de et al. Avaliação Dos Intangíveis: uma aplicação em capital humano. Gest. Prod., São Carlos, v. 15, n. 3, p. 619-634, dez. $2008 . \quad$ Disponível em<http://www.scielo.br/scielo.php?script=sci_arttext\&pid=S0104-

530X2008000300015\&lng=pt\&nrm=iso>.

Acesso em 28 ago. 2019. http://dx.doi.org/10.1590/S0104-530X2008000300015.

YIN, R. K. Estudo de Caso: planejamento e métodos. 4. ed. Porto Alegre: Bookman, 2010. 